\title{
PENURUNAN TINGKAT STRES IBU HAMIL DENGAN TERAPI MUSIK DAN AROMATHERAPY PADA KELAS IBU HAMIL
}

\author{
Ananti Setya Primawati $\mathrm{P}^{1)}$ Melyana Nurul $\mathrm{W}^{2)}$ Admini ${ }^{3)}$ \\ E-mail address: ananti.setyaa@gmail.com
}

\begin{abstract}
Preeclampsia is one of the causes of the high maternal mortality rate (MMR) in Indonesia. In Banyumas District, preeclampsia is the highest cause of MMR in JanuaryJune 2018 period. One of the risk factors of preeclampsia is the stress level in pregnancy. Prolonged levels of stress can lead to psychological changes in increased levels of adrenal and cortisol hormones. Non-pharmacological treatment techniques that can be used are music therapy and aromatherapy.

The purpose of this study was to determine the effect of the addition of music and aromatherapy therapy on pregnancy class on the stress level of pregnant women.

This research is a miniriset with the type of pre-experimental research using one group pretest posttest design. A sample of 20 pregnant women who attended pregnancy class. Measurement of stress levels was carried out before and after the intervention using the Perseived Stress Scale (PSS).

The mean level stress before the intervention 18.60 with minimum value 12 and maximum value 27. Meanwhile, the mean level stress after intervention 18.30 with minimum value 11 and maximum value 27 . There was decrease in stress levels 0.30 . Based on the results of the study, it is expected that the increase in pregnancy class is accompanied by the addition of non-pharmacological therapies to overcome psychological problems in pregnant women such as music therapy and aromatherapy.

Keywords: pregnancy class; music therapy; aromatherapy; stress; preeclampsia

1) Student of Postgraduate Midwifery Program, Poltekkes Kemenkes Semarang

${ }^{2)}$ Lecturer of Applied Health Master, Poltekkes Kemenkes Semarang

${ }^{3)}$ Midwife at Puskesmas 1 Wangon
\end{abstract}

\section{Pendahuluan}

Angka kematian ibu (AKI) dan angka kematian bayi (AKB) merupakan indikator status kesehatan masyarakat. Target Sustainable Development Goals (SDG's) tahun 2030 adalah mengurangi AKI hingga di bawah 70/100.000 kelahiran hidup (KH). Jumlah AKI di Jawa Tengah pada tahun 2017 adalah $85,58 / 100.000$ KH. Hal tersebut mengalami penurunan dibandingkan tahun 2016 yaitu 109,65/100.000 KH (21 \%) (Kemenkes RI, 2015).
Berdasarkan Profil Kesehatan Banyumas, AKI pada periode Januari-Juni 2018 adalah 122,4/100.000 KH dengan penyebab tertinggi disebabkan oleh preeklampsia $54 \%$, perdarahan $31 \%$ dan ileus $15 \%$. Jumlah kasus preeklampsia mengalami penurunan yang signifikan pada periode tahun 2014-2016. Akan tetapi, mengalami peningkatan pada tahun 2017.

Pre eklampsia merupakan komplikasi dalam kehamilan yang tidak diketahui secara pasti penyebabnya. Komplikasi yang dapat ditimbulkan 
preeklampsia pada ibu adalah solusio placenta, odema paru, hemolisis, kelainan organ seperti hati dan ginjal. Sedangkan, pada janin dapat mengakibatkan komplikasi intra uterine growth restriction (IUGR), oligohidramnion dan resiko persalinan prematur. Mekanisme komplikasi disebabkan penyempitan pembuluh darah sehingga terjadi penurunan aliran darah ke placenta(Khayati et al., 2018).

Faktor resiko terjadinya Ipreeklampsia salah satunya disebabkan tingkat stres ibu selama kehamilan. Stres akan mengaktifkan hipotalamus, sehingga terjadi desakan pelepasan hormon adrenalin dan non adrenalin di dalam tubuh. Setelah itu diikuti dengan pelepasan hormon kortisol. Apabila periode waktu stres berkepanjangan, maka tubuh secara psikologis akan mengaktifkan hormon adrenalin dan kortisol (Khayati et al., 2018).

Stres pada kehamilan dapat disebabkan riwayat persalinan sebelumnya. Penelitian menunjukkan ibu yang pernah mengalami trauma pada persalinan sebelumnya, memiliki resiko lebih tinggi tingkat stres. Selain itu, lingkungan sosial, ekonomi dan keadaan geografis dapat mempengaruhi tingkat stres ibu tergantung pada kemampuan ibu menghadapi stressor tersebut. Akibat yang dialami oleh ibu hamil berdampak pada outcome persalinan(Peoples, Thrower and Danawi, 2014).

Salah satu outcome yang disebabkan tingkat stres adalah persalinan preterm. Penelitian menunjukkan faktor resiko yang mempengaruhi persalinan preterm adalah tingkat stres ibu selama kehamilan (Lilliecreutz et al., 2016).

$$
\text { Kelas Ibu Hamil (KIH) }
$$
merupakan kegiatan bagi ibu hamil dengan tujuan meningkatkan pengetahuan mengenai kehamilan hingga masa nifas dan perawatan bayi baru lahir hingga komplikasi selama periode waktu tersebut. Di dalam KIH ibu hamil akan saling berinteraksi dan bertukar pengalaman antara ibu hamil dengan ibu hamil dan ibu hamil dengan tenaga kesehatan khususnya bidan(Kesehatan and Indonesia, 2011).

Akan tetapi, KIH konvensional lebih berfokus pada penyampaian materi dibandingkan mempersiapkan ibu menghadapi kehamilan, persalinan dan masa nifas serta memberikan kemampuan koping dalam menghadapi periode tersebut (Mastnak, 2016).

Penambahan terapi musik dan aromatherapy pada KIH diharapkan dapat meingkatkan koping ibu dan menurunkan tingkat stres. Terapi musik merupakan terapi yang digunakan pada masalah psikologi seperti kecemasan dan stres. Terapi musik dapat meningkatkan hormon endorphin sehingga ibu hamil merasa nyaman dan lebih rileks(Chang, Lin and Chang, 2017). Dalam memaksimalkan manfaat terapi musik, pelaksanaannya dapat dilakukan bersama dengan KIH.

Selain itu, penambahan aromatherapy sebagai alternatif terapi non farmakologi yang berfungsi meningkatkan produksi hormon endorphin,enkephalin dan serotonin sehingga dapatmenurunkan hormon kortisol dan mengontrol tekanan darah(Mirbastegan et al., 2016).

Oleh karena itu, peneliti tertarik untuk menganalisa pengaruh penambahan terapi musik dan aromatherapy pada kelas ibu hamil (KIH) terhadap tingkat stres ibu hamil di Puskesmas Wangon 1, Kabupaten Banyumas.

\section{Metode Penelitian}

Penelitian ini merupakan penelitian metadata analisi dengan menggunakan tinjauan literatur, yaitu menggali manfaat mengenai terapi musik dan aromatherapy dalam menurunkan tingkat stres ibu hamil. Sumber analisa berasal dari Pro-Quest, Science Direct, EBSCOhost dan Google Scholar. Jumlah jurnal penelitian sejumlah 16 penelitian mulai tahun 2014 sampai tahun 2018.

Penelitian tersebut merupakan sampel penelitian yang akan dianalisa 
menggunakan sistem penulisan daftar pustaka Harvard.

\section{Hasil dan Pembahasan}

Berdasarkan analisa beberapa penelitian dapat disimpulkan bahwa secara psikologi, perubahan yang dialami perempuan sebelum hamil menjadi hamil dan pada saat kehamilan menjadi seorang ibu merupakan salah satu stressor bagi seorang wanita terutama pada kehamilan pertama. Hal ini dikarenakan perubahan yang dirasakan adalah perubahan psikologi, sosial dan emosi ibu serta keluarga. Salah satu inovasi terapi non farmakologi adalah terapi musik. Terbukti dari penelitian yang dilakukan pada ibu hamil dapat menurunkan tingkat stress dan kecemasan terutama menghadapi persalinan. Manfaat tersebut tidak memandang usia ibu, tingkat pendidikan, agama, sosial ekonomi, jumlah paritas dan dukungan sosial (John and Angeline, 2017).

Terapi musik merupakan metode distraksi yang digunakan untuk mengalihkan perhatian terhadap rasa sakit dan kecemasan. Beberapa penelitian dilakukan pada ibu bersalin dalam menghadapi persalinan menggunakan terapi musik. Hal ini dikarenakan, musik memberikan respon stimulus terhadap rasa rileks di dalam tubuh. Penelitian dilakukan pada 60 ibu bersalin yang dibagi dua kelompok perlakuan dan kelompok kontrol menunjukkan bahwa terjadi penurunan tingkat kecemasan dan nyeri persalinan menggunakan pengukuran Visual Analogue Pain Scale (VAS) dan Zung's Self Rating Anxiety Scale (Karkal, Kharde and Dhumale, 2017).

Analisa yang dilakukan berdasarkan jurnal penelitian yang didapatkan.
Beberapa penelitian menyebutkan bahwa aromatherapy dapat menurunkan tingkat stress dan kecemasan dengan menstimulasi produksi hormon endorphin dan menurunkan hormon kortisol penyebab stress dan kecemasan. Selain itu, dapat meningkatkan kualitas tidur pasien dengan gangguan sistem kardiovaskuler (Mirbastegan et al., 2016).

Penelitian lain menyebutkan bahwa pemberian aromatherapy pada ibu postpartum dapat meurunkan kadar hormon kortisol, karena aromatherapy merupakan terapi yang merangsang indera penciuman atau inhaler. Setelah itu, diteruskan ke sistem limbik yang mengatur emosi manusia, sehingga ketika diberikan aromatherapy terjadi efek rileks pada pasien dan menurunkan hormon kortisol(Agustina C.S., Hadi, 2016).Hasil penelitian yang dilakukan membuktikan bahwa romatherapy dapat menurunkan tingkat stres dan meningkatkan hormoon prolaktin dengan penambahan massage pada ibu postpartum (Widyawati, Hadisaputro and Soejoenoes, 2016).

Berdasarkan analisa yang dilakukan mengenai efektifitas terapi musik dan aromatherapy untuk menurunkan tingkat stres, dapat disimpulkan bahwa terapi tersebut dapat menurunkan tingkat stres, kecemasan dan menignkatkan kualitas tidur. Sedangkan dalam mini riset ini, analisa yang dilakukan dihubungkan pada inovasi pemberian terapi musik dan aromatherapy untuk mengurangi tingkat stres ibu hamil yang mengikuti kelas ibu hamil. Sehingga, data yang diperoleh adalah tingkat stres ibu hamil sebelum dan sesudah dilakukan intervensi sejumlah 20 ibu hamil.

Sebelum dilakukan intervensi, peneliti menjelaskan mengenai tujuan dan manfaat kelas ibu hamil, terapi musik dan aromatherapy dalam kehamilan. Kemudian, responden mengisi lembar kehadiran dan kuesioner PSS sebelum dilakukan intervensi. Di dalam kuesioner terdapat kolom identitas berupa nama, 
umur ibu, umur kehamilan, kehamilan keberapa, pendidikan dan pekerjaan. Kegiatan kelas ibu hamil dilakukan selama kurang lebih 30 menit dengan penyampaian materi sekaligus pelaksanaan terapi musik dan aromatherapy lavender.

Pengisian kuesioner posttest dilakukan setelah dilakukan intervensi. Perubahan yang dirasakan oleh ibu hamil adalah ibu merasa tenang dan merasa lebih rileks dalam beberapa waktu. Hasil penelitian diolah menggunakan Microsoft Excel dengan melakukan coding pada bagian identitas responden.

Tabel 1. Karakteristik Responden Berdasarkan Umur Ibu, Umur Kehamilan, Tingkat Pendidikan, Jenis Pekerjaan $(\mathrm{n}=20)$

\begin{tabular}{lcc}
\hline Karakteristik & \multicolumn{2}{c}{$\begin{array}{c}\text { KIH + Terapi Musik } \\
\text { dan Aromatherapy }\end{array}$} \\
\cline { 2 - 3 } & $\mathrm{n}(\%)$ & $\begin{array}{c}\text { Median } \\
\text { (min }- \\
\text { maks })\end{array}$ \\
\hline Umur & $7(25)$ & 27 \\
- Usia Reproduksi & $21(75)$ & $(21-35)$ \\
- Terlalu Tua & & \\
- Terlalu Muda & & \\
Umur Kehamilan & $10(50)$ & 25 \\
- Trimester II & $10(50)$ & $(18-34)$ \\
- Trimester III & & \\
Tingkat Pendidikan & $15(75)$ & \\
- Dasar & $5(25)$ & \\
- Menengah & & \\
- Tinggi & & \\
Jenis Pekerjaan & $20(0)$ & \\
- IRT & $0(0)$ & \\
- PNS & $0(0)$ & \\
- Swasta & & \\
\hline
\end{tabular}

Berdasarkan tabel 1 mengenai karakteristik responden berdasarkan umur ibu, umur kehamilan, tingkat pendidikan dan jenis pekerjaan. Didapatkan data bahwa umur ibu dibagi sesuai kategori umur reproduksi sejumlah $6(30 \%)$ dan terlalu tua 14 (70) dengan rerata umur ibu 27 tahun dan umur termuda 21 tahun dan tertua 34 tahun. Sedangkan, umur kehamilan dibagi berdasarkan trimester kehamilan yaitu trimester II $10(50 \%)$ dan trimester III $10 \quad(50 \%)$. Tingkat pendidikan ibu hamil dibagi menjadi tiga yaitu pendidikan dasar 15 (75), pendidikan menengah 5 (25\%) dan pendidikan tinggi $0(0 \%)$. Karakteristik terakhir adalah jenis pekerjaan ibu yaitu sebagai Ibu rumah tangga $20(100 \%)$.

Tabel 2. Tingkat Stres Pretest dan Posttest $(\mathrm{n}=20)$

\begin{tabular}{cccccc}
\hline & & \multicolumn{3}{c}{ KIH + Terapi Musik dan } \\
Anterval & & \multicolumn{3}{c}{ Aromatherapy } \\
Persen & Kriteria & \multicolumn{2}{c}{ Pretest } & \multicolumn{2}{c}{ Postest } \\
& & $\mathrm{f}$ & Mean & $\mathrm{f}$ & Mean \\
& & $(\%)$ & & $(\%)$ & \\
\hline $0-13$ & Stres & 2 & & 1 & \\
& Ringan & $(10)$ & 18,60 & $(5)$ & 18,30 \\
$14-26$ & Stres & 17 & & 18 & \\
& Sedang & $(85)$ & & $(90)$ & \\
$27-40$ & Stres & 1 & & 1 & \\
& Berat & $(5)$ & & $(5)$ & \\
\multicolumn{2}{c}{ Jumlah } & 20 & & 20 & \\
\hline
\end{tabular}

Berdasarkan tabel 2 mengenai tingkat stres sebelum dilakukan intervensi, didapatkan dari 20 ibu hamil yaitu tingkat stres ringan $2(10 \%$, stres sedang 17 (85 $\%)$ dan stres berat $1(5 \%)$. Sedangkan, tingkat stres setelah dilakukan intervensi yaitu stres ringan $1(5 \%)$, stres sedang 18 (90 \%) dan stres berat 1 (5\%). Penurunan rerata tingkat stres sebelum dan sesudah intervensi adalah 18,60 menjadi 18,30 yaitu sebesar 0,30.

Kelas ibu hamil dilakukan setiap bulan mulai dari trimester pertama. Akan tetapi, pelaksanaan kelas ibu hamil di Puskesmas Wangon 1 dimulai pada saat umur kehamilan ibu memasuki trimester II, hal ini dikarenakan terdapat pelaksanaan senam hamil.

Berdasarkan umur ibu, jumlah ibu dengan kategori terlalu tua $21(75 \%)$ berpengaruh terhadap kesiapan ibu menghadapi persalinan dan kemampuan diri menghadapi stresor(Gibbs et al., 2012). Berdasarkan data responden, didapatkan bahwa pendidikan ibu paling banyak adalah pendidikan dasar 15 (75 $\%)$. Hal ini didukung faktor umur ibu 
dalam hal mengingat materi yang sudah disampaikan.

Salah satu faktor yang mempengaruhi tingkat stres ibu adalah dukungan sosial dan lingkungan. Tenaga kesehatan khususnya bidan melakukan pendampingan terhadap ibu hamil melalui $\mathrm{KIH}$ diharapkan mampu meningkatkan interaksi sehingga ibu merasakan dukungan dari bidan(Abushaikha and Sheil, 2006). Hal ini sesuai dengan hasil penelitian bahwa terdapat penurunan tingkat stres setelah dilakukan intervensi.

Pelaksanaan KIH disertai dengan terapi musik dan aromatherapy. Terapi musik yang digunakan dalam pelaksanaan intervensi adalah jenis musik mozart. Meskipun penurunan tingkat stres tidak signifikan, akan tetapi penambahan terapi musik dalam kegiatan $\mathrm{KIH}$ berhubungan dengan kualitas kemampuan ibu dalam perawatan bayi baru lahir dan kualitas hubungan dengan keluarga (Chang, Lin and Chang, 2017).

Jenis musik yang digunakan berpengaruh pada penerimaan ibu selama perlakuan. Hal ini terbukti dari penelitian yang menyebutkan bahwa musik dapat meningkatkan kecerdasan janin, stimulasi proses pembentukan organ janin terutama pada trimester awal. Selain itu, musik Mozart meningkatkan kemampuan kognitif ibu serta mengatur kebiasaan tidur ibu ketika postpartum(Mastnak, 2016).

Perubahan fisiologis pada kehamilan menyebabkan beberapa keluhan seperti sakit punggung dan nyeri otot sehingga menyebabkan perasaan tidak nyaman. Hal ini dapat dijadikan faktor presdiposisi terjadinya stres pada kehamilan. Penelitian menyebutkan bahwa terapi musik dapat dijadikan sebagai audio-analgesia atau anastesi oral pada kehamilan untuk mengurangi nyeri dan ketidaknyamanan kehamilan(Surucu et al., 2017). Penelitian mengenai aromatherapy, merupakan salah satu pengobatan non farmakologi dengan menstimulasi reseptor dan mengirimkan pada sistem limbik untuk melepaskan hormon endorphin, enkephalin dan serotonin sehingga terjadi penurunan tingkat stres(Mastnak, 2016).

Pelaksanaan intervensi dilakukan menggunakan aromatherapy lavender yang terbuat dari ekstrak bunga lavender. Terdapat beberapa penelitian menyebutkan bahwa lavender dapat memberikan efek relaksasi dan antispasmodik dengan kandungan utama asam linalool asetat dan digunakan sebagai obat analgesik. Mekanisme terjadi ketika essential oil lavender dapat menstimulasi reseptor yang terdapat dalam indra penciuman dan merelease hormon endorphin, encephalin dan serotonin. Hormon tersebut berfungsi untuk relaksasi dan menurunkan stress (Najafi and Tagharrobi, 2014).

Berdasarkan penjelasan tersebut, meskipun penurunan rerata tingkat stres tidak signifikan. Dapat disimpulkan bahwa terdapat pengaruh penambahan terapi musik dan aromatherapy pada kelas ibu hamil terhadap tingkat stres ibu hamil di Puskesmas Wangon 1, Kabupaten Banyumas.

\section{Simpulan}

Simpulan dari penelitian adalah (1) Karakteristik responden dengan umur ibu terlalu tua 14 (70 \%), tingkat pendidikan dasar $15(75 \%)$ dan jenis pekerjaan IRT $20(100 \%)$ menjadi faktor tingkat stres pada ibu hamil. (2) Rerata penurunan tingkat stres adalah 0,30 setelah dilakukan intervensi. Berdasarkan simpulan tersebut, diharapkan penelitian miniriset ini dapat diteruskan dengan penambahan jumlah responden dan area tempat penelitian sehingga dapat dianalisa lebih mendalam.

Saran yang dapat diberikan
kepada tenaga kesehatan adalah meningkatkan kualitas pelayanan dengan memperhatikan psikologis pasien. Kepada masayarakat untuk meningkatkan 
dukungan dan keaktifan serta peran serta dalam perawatan ibu.

\section{Ucapan terimakasih}

Ucapan terimakasih kami sampaikan kepada seluruh pegawai Puskesmas Wangon 1, Kabupaten Banyumas dan Dinas Kesehatan Kabupaten Banyumas yang telah memberikan izin serta bantuan dalam penelitian miniriset tersebut.

\section{Daftar Pustaka}

Abushaikha, L. and Sheil, E. P. (2006) 'Labor Stress and Nursing Support: How do They Relate?', Journal of International Women's Studies, 7(4), pp. 198-208. Available at: http://vc.bridgew.edu/jiws/vol7/iss4 $/ 13$.

Agustina C.S., Hadi, M. N. W. (2016) 'Aromatherapy Massage As An Alternative in Reducing Cortisol Level and Enhancing Breastmilk Producing on Primiparaous Postpartum Women in Semrang, Globalizing Asia: Integrating Science, Technology and Humanities for Future Growth and Development, pp. 381-388.

Chang, Y. Y., Lin, C. L. and Chang, L. Y. (2017) 'The Effects of Aromatherapy Massage on Sleep Quality of Nurses on Monthly Rotating Night Shifts', Evidencebased Complementary and Alternative Medicine, 2017. doi: $10.1155 / 2017 / 3861273$.

Gibbs, C. M. et al. (2012) 'The impact of early age at first childbirth on maternal and infant health', Paediatric and Perinatal Epidemiology, 26(SUPPL. 1), pp. 259-284. doi: 10.1111/j.13653016.2012.01290.x.

John, N. and Angeline, A. (2017) 'Effectiveness of Music Therapy on
Anxiety and Pain among Mothers During First Stage of Labour in Selected Hospitals at Kollam', International Journal of Nursing Education, 9(2), p. 24. doi: 10.5958/0974-9357.2017.00030.7.

Karkal, E., Kharde, S. and Dhumale, H. (2017) 'Effectiveness of Music Therapy in Reducing Pain and Anxiety among Primigravid Women during Active Phase of First Stage of Labor', International Journal of Nursing Education, 9(2), p. 57. doi: 10.5958/09749357.2017.00036.8.

Kemenkes RI (2015) Profil Kesehatan Indonesia, Kemenkes RI. doi: 10.1111/evo.12990.

Kesehatan, K. and Indonesia, R. (2011) 'KEMENTERIAN KESEHATAN REPUBLIK INDONESIA TAHUN 2011'.

Khayati, Y. N. et al. (2018) 'STRESS', $1(1)$.

Lilliecreutz, C. et al. (2016) 'Effect of maternal stress during pregnancy on the risk for preterm birth', $B M C$ Pregnancy and Childbirth. BMC Pregnancy and Childbirth, 16(1), pp. 1-9. doi: 10.1186/s12884-0150775-x.

Mastnak, W. (2016) 'Perinatal Music Therapy and Antenatal Music Classes: Principles, Mechanisms, and Benefits', The Journal of Perinatal Education, 25(3), pp. 184-192. doi: 10.1891/10581243.25.3.184.

Mirbastegan, N. et al. (2016) 'Effects of Aromatherapy on Anxiety and Vital Signs of Myocardial Infarction Patients in Intensive Care Units', 15(2).

Najafi, Z. and Tagharrobi, Z. (2014) 
'Effect of aromatherapy with Lavender on sleep quality among patients undergoing hemodialysis Abstract: Background: Sleep disorders are one of the most common problems in patients undergoing hemodialysis. The purpose of this study was to examine the effect of aromatherapy on sleep quality in hemodialysis patients . Materials and Methods : This clinical trial was performed on 60 hemodialysis patients selected from the dialysis centers of Akhavan hospital in Kashan and Shohadaye Lenjan hospital in Zarrinshahr . Eligible patients were randomly assigned into two equal groups, the experimental and control groups. The experimental group smelled lavender essential oil during the study, while the control group received no intervention. The Persian and the end of study . sleep quality in hemodialysis patients and may be used as a noninvasive , easy and low-cost', 18(2), pp. 145-150.

Peoples, M., Thrower, A. and Danawi, H. (2014) 'Exploring the Impact of Stress on Pregnancy Loss.', International Journal of Childbirth Education, 29(3), pp. 80-83. Available at: http://search.ebscohost.com/login.as $\mathrm{px}$ ?direct=true $\& \mathrm{db}=\mathrm{jlh} \& \mathrm{AN}=10385$ $9814 \&$ site $=$ ehost-live.

Surucu, S. G. et al. (2017) 'The effect of music on pain and anxiety of women in labor during their first pregnancy: A study from Turkey Complementary Therapies in Clinical Practice The effect of music on pain and anxiety of women during labour on fi rst time pregnancy: A study from Turkey', Complementary Therapies in Clinical Practice. Elsevier Ltd, 30(February 2018), pp. 96-102. doi: 10.1016/j.ctcp.2017.12.015.

Widyawati, M. N., Hadisaputro, S. and Soejoenoes, A. (2016) 'Effect of Massage and Aromatherapy on Stress and Prolactin Level Among Primiparous Puerperal Mothers in Semarang, Central Java ', Belitung Nursing Journal, 2(4), pp. 48-57. 